\section{Herpes simplex virus esophagitis in an immuno- deficient patient with non-small-cell lung cancer following a disseminated herpes zoster infection}

Herpes simplex virus (HSV) esophagitis is rare. It usually occurs in the setting of immunodeficiency, for example in patients with malignancy [1], patients on immunosuppressive therapy [2], or patients with AIDS [3].

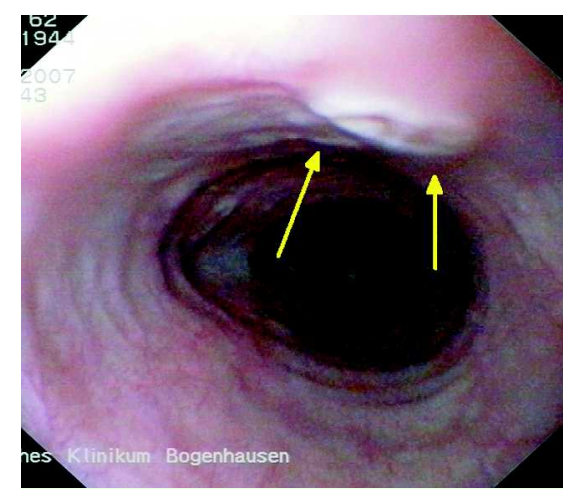

Fig. 1 Upper gastrointestinal endoscopy revealed coin-shaped, white pseudomembranous lesions, $1-2 \mathrm{~cm}$ in diameter, with a discrete central ulcer in the proximal portion of the esophagus (arrows).
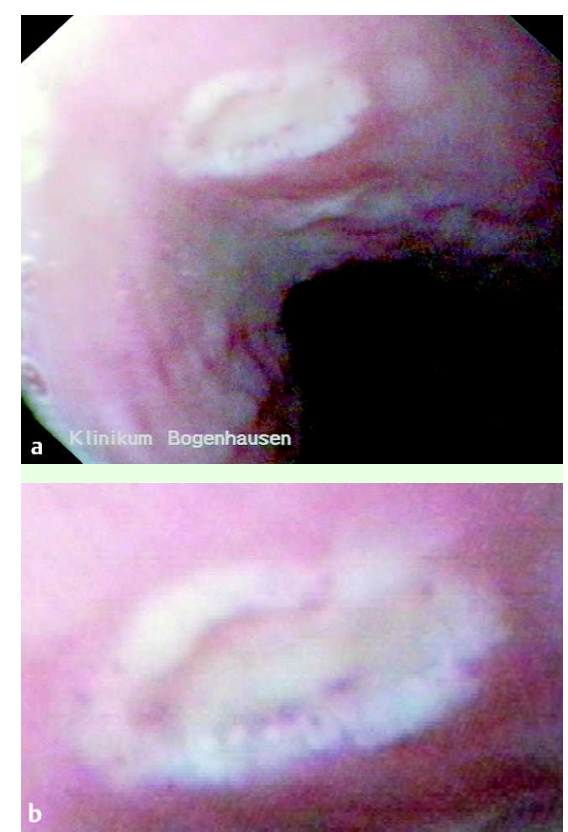

Fig. 2 A histological view showing typical histological changes associated with herpetic lesions, including a ground-glass appearance of the nuclear chromatin, nuclear inclusions, and multinucleation (periodic acid-Schiff reaction, original magnification $\times 100)$.
A 62-year-old patient with non-small-cell lung cancer (T3N2M1) presented with a 1-month history of persistent dysphagia and odynophagia. Eight weeks before, he had undergone whole-brain radiation therapy for multiple cerebral metastases. A few days later, the patient developed disseminated herpes zoster, secondary to the immunosuppression caused by the radiation. He received systemic therapy with intravenous aciclovir $(10 \mathrm{mg} / \mathrm{kg}$ per day) for 14 days, resulting in complete recovery of the skin lesions.

Upper gastrointestinal endoscopy revealed numerous, coin-shaped, white pseudomembranous lesions, $1-2 \mathrm{~cm}$ in diameter, with a discrete central ulcer in the proximal portion of the esophagus which bled readily ( $\bullet$ Fig. 1 ). The stom- ach and duodenum were normal. Herpes virus infection was not suspected as the cause of the esophagitis at endoscopy. However, biopsy specimens showed typical herpetic histological changes, including a ground-glass appearance of the nuclear chromatin, nuclear inclusions, and multinucleation ( $\bullet$ Fig. 2 ), and positive immunostaining with specific anti-HSV type 1 antibodies ( $\bullet$ Fig. 3), appearances supporting the diagnosis of herpetic esophagitis.

Because inflammatory parameters were not significantly elevated and because the patient showed no signs of systemic herpes virus infection or relapse of herpes zoster, he was not given antiviral chemotherapy. A repeat endoscopy 2 weeks later showed a marked spontaneous improvement and the patient's initial symptoms had resolved. To date, the HSV esophagitis has not relapsed (after 3 months).

Proper endoscopic interpretation is a prerequisite for the recognition of herpes esophagitis because biopsy and culture results can be negative in the early stages of this condition [4]. However, failure to
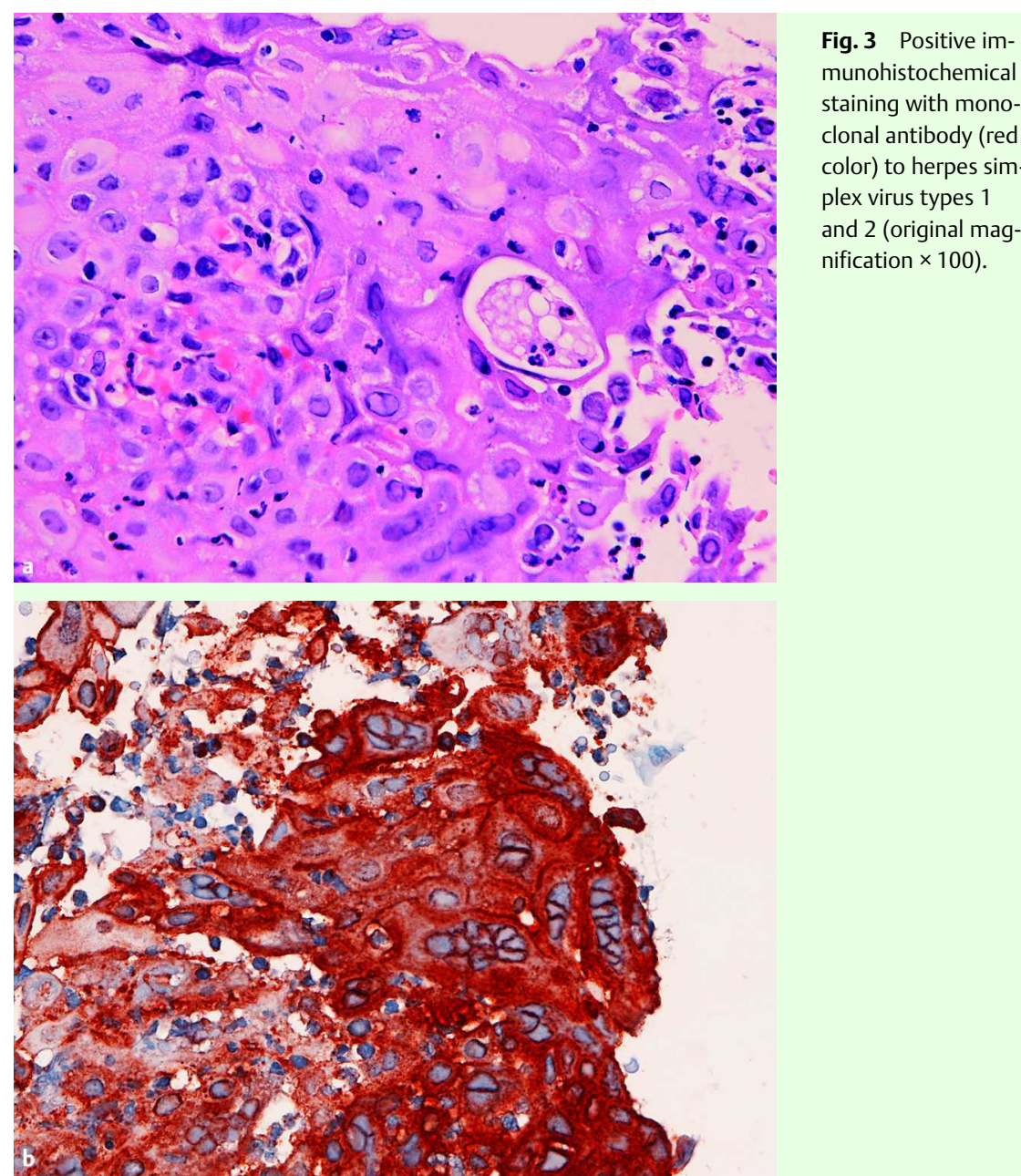
diagnose HSV esophagitis can result in gastrointestinal bleeding caused by herpetic esophageal ulcers [5]. We conclude that physicians who are treating patients with malignancies should be aware of the potential of patients to develop HSV esophagitis, especially as effective antiviral agents are now available.

Endoscopy_UCTN_Code_CCL_1AB_2AC_3AZ

F. Gundling ${ }^{1}$, H. Rohrbach ${ }^{2}$, A. Nerlich ${ }^{2}$, W. Schepp

1 Second Department of Medicine, Bogenhausen Academic Teaching Hospital, Technical University of Munich, Munich, Germany

2 Department of Pathology, Bogenhausen Academic Teaching Hospital, Technical University of Munich, Munich, Germany

\section{References}

1 Matsumoto J, Sumiyoshi A. Herpes simplex esophagitis: a rare study in autopsy series. Am J Clin Pathol 1985; 84: 96-99

2 McDonald DB, Sharma P, Hackman RC et al. Esophageal infections in immunosuppressed patients after bone marrow transplantation. Gastroenterology 1985; 88: 1111 1117

3 Wilcox CM, Schwartz DA, Clark WS. Esophageal ulceration in human immunodeficiency virus infection: causes, response to therapy, and long-term outcome. Ann Intern Med 1995; 122: $143-149$

4 Kadakia SC, Oliver GA, Peura DA. Acyclovir in endoscopically presumed viral esophagitis. Gastrointest Endosc 1987; 33: 33-35

5 Rattner HM, Cooper DJ, Zaman MB. Severe bleeding from herpes esophagitis. Am Gastroenterol 1985; 80: 523-525
Bibliography

DOI 10.1055/s-2007-995380

Endoscopy 2007; 39: E157-E158

(c) Georg Thieme Verlag KG Stuttgart · New York . ISSN 0013-726X

Corresponding author

\section{F. Gundling, MD}

Department of Gastroenterology, Hepatology and Gastrointestinal Oncology Bogenhausen Academic Teaching Hospital Technical University of Munich Englschalkinger Straße 77 81925 Munich

Germany

Fax: +49-89-92702486

Gastroenterologie@kh-bogenhausen.de 